\title{
Here comes the sun: the era of genetics
}

\author{
Aí vem o sol: a era da genética \\ Fernando Kok
}

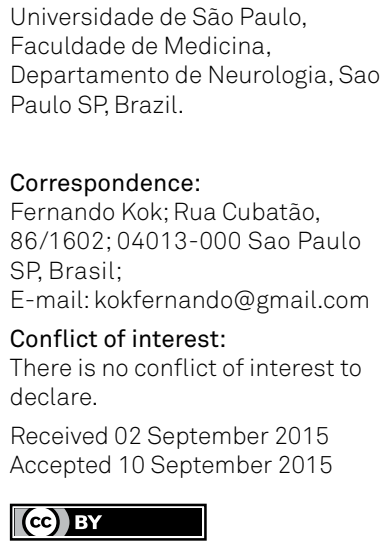

Received 02 September 2015 Accepted 10 September 2015

\section{(cc) BY}

I

$\mathrm{n}$ this number of Arquivos de Neuropsiquiatria, a comprehensive and welcomed review on genetics of epileptic encephalopaties (EE) is presented by Gonsales and cols ${ }^{1}$.

As we can easily recognize, knowledge come in cycles, which establish the foundations for the following cycle of knowledge and is by his turn modified by the disruptive newcomer. The era of clinical seizures characterization, exemplified by the description by West in 1841, on his own child, of what we know today by infantile (or epileptic) spasms, or the recognition of petit mal, now known as absence seizures. Since the groundbreaking effort more than a century ago for establishing the fundaments of clinical classification of epileptic seizures, seizures classification is continuously rewritten to incorporate new knowledge.

The era of clinical and electrographical correlation, inaugurated by the development of the first EEG recordings, by Hans Berger in in 1924, which allowed in the following years the determination of electrophysiological patterns of epilepsy and contributed to the definition of several epileptic syndromes. Incremental innovations, as continuous electrographical monitoring and videoeletrencephalogram developments further improve our knowledge.

The era of imaging studies humbly started with the development of X-ray, able to recognize not much else than brain calcifications, passing to CT-scan and achieving its heyday with MRI and its unsurpassed ability for recognizing subtle changes in brain parenchyma and to pinpoint epileptogenic lesions. Combined with clinical and electrographical data, allowed advances in the surgical procedures and a better understanding of epilepsy physiopathology. Other imaging techniques, as SPECT and PET-scan allowed better correlation between an epileptic focus and cerebral blood flow.

And now we are living the era of genetics, or of molecular epilepsy. The arrival of next generation sequencers together with new bioinformatics tools allowing processing of huge amount of data, brought an avalanche of new findings regarding the molecular basis mostly of the more severe spectrum of epilepsy, the EE. Our understanding of the genetics of well-established conditions in epileptology, as Otahara, West, Dravet, Doose and Lennox-Gastaut syndromes is changing the way we investigate and even treat some of this disorders.

Genetically determined EE are usually caused by a discreet change in a single copy of one gene, which can start a catastrophic molecular cascade leading to severe epilepsy. In most cases, these changes are not inherited from the parents, but occurred as a de novo mutation. So, in most cases, family history of epilepsy will not be present in a remarkable way.

Genetic tests for EE using this new technology are now available in clinical practice, either as panel of genes for epilepsy or as whole exome sequencing, in which all 200,000 exons of the $\sim 20,000$ genes are sequenced. In this late case, almost all genetic conditions associated with severe epilepsy can be investigated in a single test; and it is also possible to review results previously emitted to incorporate information regarding new associations of genes with epilepsy. Finally, new bioinformatics protocols for next generation sequencing are allowing determination of copy number variations (CNVs) and in this way detecting abnormalities without the use of chromossomal microarray.

It is well known for many decades that epilepsy susceptibility has a genetic component and that conditions as febrile seizures, rolandic epilepsy and absence seizures can run in families. Unraveling what are the genes that can give susceptibility for these conditions is still a challenge, and we have only get some hints. The interaction between different gene products and environmental factors make the interpretation of molecular findings even more difficult and restricts the clinical use of the new technologies of genetic analysis. 
As commonly happens with reviews of hot topics, by the time it is published it is already outdated. Since the submission and approval of this outstanding review, at least five more genes were associated with $\mathrm{EE}^{2,3,4,5,6}$. And by the time this editorial comes to print, some others certainly will be published. We all hope that the coming sun of Genetics era brings better understanding and treatment for epilepsy in general and of epileptic encephalopathies in particular.

\section{References}

1. Gonsales MC, Montenegro MA, Soler CV, Coan AC, Guerreiro MM, Lopes-Cendes I. Recent developments in the genetics of childhood epileptic encephalopathies: impact in clinical practice. Arq Neuropsiquiatr. 2015;73(11):946-58. doi:10.1590/0004-282X20150122

2. Abidi A, Mignon-Ravix C, Cacciagli P, Girard N, Milh M, Villard L. Early-onset epileptic encephalopathy as the initial clinical presentation of WDR45 deletion in a male patient. Eur J Hum Genet. 2015 Jul 15. doi:10.1038/ejhg.2015.159 [Epub ahead of print]

3. Chung WK, Martin K, Jalas C, Braddock SR, Juusola J, Monaghan KG et al.. Mutations in COQ4, an essential component of coenzyme Q biosynthesis, cause lethal neonatal mitochondrial encephalomyopathy. J Med Genet. 2015;52(9):627-35. doi:10.1136/jmedgenet-2015-103140
4. Conroy J, Allen NM, Gorman KM, Shahwan A, Ennis S, Lynch SA et al. NAPB: a novel SNARE-associated protein for early-onset epileptic encephalopathy. Clin Genet. 2015 Aug 3. doi:10.1111/cge.12648 [Epub ahead of print]

5. Nieh SE, Madou MR, Sirajuddin M, Fregeau B, McKnight D, Lexa K et al. De novo mutations in KIF1A cause progressive encephalopathy and brain atrophy. Ann Clin Transl Neurol. 2015;2(6):623-35. doi:10.1002/acn3.198

6. Hansen J, Snow C, Tuttle E, Ghoneim DH, Yang CS, Spencer A et al. De novo mutations in SIK1 cause a spectrum of developmental epilepsies. Am J Hum Genet. 2015;96(4):682-90. doi:10.1016/j.ajhg.2015.02.013 